\title{
Expansion treatment using Invisalign®: Periodontal health status and maxillary buccal bone changes. A clinical and tomographic evaluation.
}

\author{
Graciela J. Barreda ${ }^{1,2}$, Elizabeth A. Dzierewianko ${ }^{1,2}$, Valeria Mazza ${ }^{1,2,3}$, Karina A. Muñoz ${ }^{1,2}$, \\ Gisela I. Piccoli' 2, Hugo J. Romanelli ${ }^{2,3}$ \\ ${ }^{1}$ Sociedad Argentina de Ortodoncia. Departamento de investigaciones. Buenos Aires, Argentina. \\ 2 Universidad de Ciencias Empresariales y Sociales, Buenos Aires, Argentina. \\ ${ }^{3}$ Universidad Maimónides. Facultad de Odontología. Departamento de investigaciones Odontológicas. Buenos Aires, \\ Argentina.
}

\begin{abstract}
The aim of this study was to evaluate changes in periodontal status and maxillary buccal bone by considering clinical and tomographic parameters during the first year of orthodontic expansion with Invisalign ${ }^{\circledR}$ aligners. Upper first (1PM) and upper second (2PM) premolars of 19 patients with orthodontic expansion requirement treated with Invisalign ${ }^{\circledR}$ aligners were evaluated. Plaque index (PI), gingival index (GI), probing pocket depth (PPD), clinical attachment level (CAL) and cone beam tomographic (CBCT) records were collected at 76 sites before starting treatment (TO) and at 12 months (T1). Bone height was measured from cementoenamel junction (CEJ) to the crest cortical bone (CC). Bone thickness was measured at two levels: $4 \mathrm{~mm}(C E J+4)$ and $6 \mathrm{~mm}(C E J+6)$ apical to the CEJ. A descriptive analysis was made of the variations of bone thickness and height in a series of cases. The average expansion was $1.93 \mathrm{~mm}$ for 1PM and $167 \mathrm{~mm}$ for 2PM. Arithmetic mean
\end{abstract}

of distance CEJ-CC in IPM was $3.05 \mathrm{~mm}$ at T0, and remained at $3.05 \mathrm{~mm}$ at T1. Arithmetic mean of distance CEJ-CC in $2 P M$ was $2.06 \mathrm{~mm}$ at T0 and 2.31 at T1. Post-expansion, most of the analyzed sites (86\%) exhibited a bone thickness of $\geq 0.5$ $\mathrm{mm}$. The greatest variations between $T 0$ and $T 1$ were observed at the level of 1PM CEJ+ 4 and 2PM CEJ+ 6. The minimal changes in the clinical records (GI, PI, PPD and CAL) between $T 0$ and $T 1$ were compatible with the maintenance of gingivalperiodontal health. Invisalign ${ }^{\circledR}$ for expansion movements did not produce substantial changes in the evaluated periodontal clinical parameters or in the bone measurements. Removable appliances reduce plaque retentive factors and favor adequate oral hygiene.

Received: March 2020; Accepted: June 2020.

Keywords: clear aligner appliances- periodontium- cone beam computed tomography-facial bones.

\section{Tratamiento de expansión con Invisalign $\AA$ : estado de salud periodontal y cambios óseos maxilares. Evaluación clínica y tomográfica.}

\begin{abstract}
RESUMEN
El objetivo de este estudio fue evaluar los cambios en el estado periodontal y hueso facial maxilar a través de parámetros clínicos y tomográficos durante la expansión ortodóncica con alineadores Invisalign ${ }^{\circledR}$ en el primer año de tratamiento. Se evaluaron los primeros (1PM) y segundos (2PM) premolares superiores pertenecientes a 19 pacientes con requerimiento de expansión ortodóncica tratados con alineadores Invisalign ${ }^{\circledR}$. Se registraron los índices de placa (IP), indice gingival (IG), profundidad al sondaje (PS) y nivel de inserción (NI) y registros tomográficos de haz cónico (CBCT) en 76 sitios antes de comenzar el tratamiento (T0) y a los 12 meses (T1). Se midió la altura ósea desde el límite amelocementario (LAC) hasta la cortical de la cresta (CC) y el espesor en dos niveles; a $4 \mathrm{~mm}$ $(L A C+4)$ y a $6 \mathrm{~mm}(L A C+6)$ hacia apical del LAC. Se realizó un análisis descriptivo de las variaciones de la altura y espesor óseo en una serie de casos. La expansión promedio para IPM fue de 1,93 mm y para 2PM fue de 1,67 mm. La media
\end{abstract}

aritmética de LAC-CC en primeros premolares fue de 3,05 $\mathrm{mm}$ en T0 y se mantuvo el valor de 3,05 $\mathrm{mm}$ en T1. La media aritmética de $L A C-C C$ en segundos premolares fue de 2,06 $\mathrm{mm}$ en T0 y 2,31 en T1. Post expansión, la mayoría de los sitios (86\%) analizados exhibieron un espesor óseo $\geq 0,5 \mathrm{~mm}$. Las mayores variaciones entre T0 y T1 se observaron a nivel de $1 P M C E J+4$ y $2 P M$ CEJ+6. Los registros clínicos (PI, GI, PPD y CAL) evidenciaron mínimos cambios entre T0 y T1, compatibles con el mantenimiento de la salud gíngivo-periodontal. El uso de Invisalign ${ }^{\circledR}$ para movimientos de expansión no produjo cambios sustanciales en los parámetros clínicos periodontales evaluados ni en las mediciones óseas. La aparatología removible reduce los factores retentivos de placa bacteriana y facilita una adecuada higiene oral.

Palabras clave: alineadores ortodóncicos transparentes- periodoncio- tomografía computarizada de haz cónico- huesos faciales. 


\section{INTRODUCTION}

The number of adult patients requiring orthodontic treatment has increased noticeably in recent decades and Clear Aligner Therapy (CAT) has become an option for patients requiring comfort and esthetics consistent with current lifestyle ${ }^{1-3}$.

The relationship between orthodontic treatments and periodontal health has always been a matter of concern to orthodontists and periodontists, whether as a result of the forces applied or due to the changes produced by orthodontic movement in both the bone and the soft tissues ${ }^{4,5}$. Mild or moderate dental crowding, narrow arches or crossbites can be resolved by dentoalveolar expansion. The literature has shown that dentoalveolar expansion is the movement that most compromises the buccal bone ${ }^{6-9}$. Technological advances in imaging have enabled detailed evaluation of facial bone by using cone beam computed tomography $(\mathrm{CBCT})^{3,10-12}$.

The effects on alveolar bone and soft tissues in patients treated with fixed orthodontic appliances were extensively evaluated with two-dimensional radiographs until the advent of computed tomography ${ }^{4}$. Mandelaris mentioned that the American Academy of Periodontology Consensus of 2017 agreed that CBCT is the only radiographic mode that enables objective detection and prediction of changes in the facial bone and the general structure of the alveolar bone ${ }^{10}$. While there is limited evidence supporting routine use of CBCT in orthodonticperiodontal therapy, experts agree that its use should be considered in various scenarios, including adult patients with dentoalveolar deficiencies (crowding and/or transverse discrepancies) which require expansion, thin periodontal phenotype and recessions, among others ${ }^{8}$.

Considering that there is plentiful evidence of the presence of bone dehiscence and fenestrations in patients who have never undergone orthodontic treatment, it is very important to diagnose these conditions in order to minimize risk during expansion $^{13,14}$. Some studies have shown that maxillary facial alveolar bone decreases after dentoalveolar expansion when fixed appliances are used $^{15}$.

There are several studies on the thickness of the buccal plate of maxillary incisors and canines, but relatively few on the thickness of the facial plate of premolars. Results vary according to the method used for measuring. The facial plate is significantly thinner for the upper first premolar than for the upper second premolar, due to root morphology and more anterior position in the arch, among other factors ${ }^{5,11,12,16-22}$. Average alveolar bone thickness in the premolar zone is $1.13 \mathrm{~mm}$ measured at $1 \mathrm{~mm}$ apical to the crest, and $1.03 \mathrm{~mm}$ at mid-root ${ }^{23}$.

Although CBCT can provide plentiful information, it is also essential to record gingival-periodontal clinical parameters periodically. The treatment plan should evaluate the risk of alterations at gingival level as well as attachment loss. Periodontal health should be considered as an important factor in the success of an orthodontic treatment.

Oral hygiene procedures have major impact on periodontal health during orthodontic treatment. The literature supports the link between increase in bacterial plaque indexes and decline in oral health conditions in patients under orthodontic treatment, especially when fixed appliances are used. CAT can minimize the negative orthodontics-related effects on health by enabling simpler oral hygiene procedures $^{2,24-27}$.

The aim of this study was to evaluate changes in periodontal status and alveolar bone in a series of cases by considering clinical and tomographic parameters during the first year of orthodontic expansion with Invisalign ${ }^{\circledR}$ aligners.

\section{MATERIALS AND METHODS}

This study was approved by the Ethics Committee of the Argentine Society of Orthodontics on August 1, 2016. All patients signed the informed consent form accepting to participate voluntarily in the clinical study. The study protocol was in agreement with the Helsinki declaration of 1975, reviewed in 2013.

Twenty-three patients with orthodontic expansion indication and high esthetic demand, who were referred by the Admissions Department of the Argentine Society of Orthodontics from 2016 to 2018, were evaluated for treatment with Invisalign ${ }^{\circledR}$ aligners. Nineteen of these patients met the inclusion criteria and were selected to participate in the study: 16 females and 3 males, 15 to 50 years of age.

Inclusion criteria were: complete dentition, mild or moderate tooth crowding, with indication of expansion, with healthy or normalized periodontium, non-smokers. Exclusion criteria were: crowns in the upper jaw, extensive restorations, presence of carious lesions, pregnancy, presence of systemic diseases contraindicating orthodontic treatment, 
history of head and neck radiation, regular use of steroids or any other medication affecting bone turnover.

All patients received an oral hygiene protocol: Bass Technique with soft toothbrush (Colgate ${ }^{\circledR}$ Slimsoft) use of dental floss, interdental brushes or picks. Use of electric toothbrush was not allowed. Recommended frequency for tooth cleaning was twice a day.

After recording periodontal indexes and performing tomographic studies, orthodontic treatment with aligners was begun. Patients were scheduled once a month for follow-up. Aligners were to be used 22 hours a day and changed every 15 days.

For this study, in the 19 selected patients, the upper first (1PM) and upper second (2PM) premolars were analyzed. Clinical and tomographic measurements were taken before beginning expansion treatment (T0) and at 12 months (T1).

\section{Clinical records}

The following indexes were recorded for buccal and proximal surfaces of upper first and second premolars:

- Löe and Silness plaque index (PI) ${ }^{28}$

- Silness and Löe gingival index (GI) ${ }^{29}$

- Probing pocket depth (PPD)

- Clinical attachment level (CAL)

Measurements were taken with a periodontal probe marked in millimeters (North Carolina; Hu Friedy ${ }^{\circledR}$, Chicago IL) and rounded to the nearest millimeter on the probe scale.

\section{Analysis of tomographic images}

Facial bone thickness and height in maxillary premolars were examined by using CBCT, which provides $0.123 \mathrm{~mm}$ image resolution, enabling precise linear measurements with low exposure to radiation. Thicknesses under $0.12 \mathrm{~mm}$ might not be detected. Tomographic images were taken with 3D Accuitomo (J. Morita MFG Co., Kyoto, Japan). The scans were taken in a single 360 -degree rotation at a scan time of 17 seconds, $90 \mathrm{Kvp}, 0.125 \mathrm{~mm}$ voxel size and $60 \times 60 \mathrm{~mm}$ field of view (FOV). Patient head was positioned locating Camper's Plane parallel to the ground and the midsagittal plane perpendicular to it. Position was held by headrest, headband and chinrest.

After the CBCT scans, a protocol was established to capture pre- and post-treatment images of selected teeth $(1.4,1.5,2.4$ and 2.5) using One Volume software (J Morita MFG Co. Kyoto, Japan) in order to evaluate any changes in height and thickness of the facial bone.

Standardization of positioning of the tooth to be evaluated

A standardized orientation was established, and a protocol was followed.

1. Axial-guided navigation was used as reference to locate landmarks.

2. On the axial section, the image was positioned such that the vertical was tangential to the vestibular surface of the selected teeth, while the major axis coincided with the horizontal

3. On the coronal plane, the image was positioned such that the line passing through the buccal and palatal cementoenamel junctions coincided with the horizontal axis

Both sections were adjusted simultaneously (Fig 1).

\section{Measurements}

Image files were processed in a conventional computer using Image $\mathrm{J}(\mathrm{NIH})$ software on a Lenovo monitor with $1280 \times 1024$ pixel resolution. All measurements were taken by a single examiner (VM).

The following measurements were taken on the coronal section (Fig 2):

- Distance from the cementoenamel junction (CEJ) to the alveolar crest (CC): CEJ-CC

- Thickness of facial bone $4 \mathrm{~mm}$ apical to the CEJ: CEJ+4

- Thickness of facial bone $6 \mathrm{~mm}$ apical to the CEJ: CEJ+6

\section{Transverse measurements}

Digital models from Align Technology Clincheck ${ }^{\circledR}$ were obtained at $\mathrm{T} 0$ and $\mathrm{T} 1$. Linear values of upper arch width were measured for interfirst and intersecond premolars.

Figs 3 and 4 show clinical, virtual models and tomographic images at $\mathrm{T} 0$ and $\mathrm{T} 1$.

\section{RESULTS}

The average expansion was $1.93 \mathrm{~mm}$ (range 0.5 to $5.1 \mathrm{~mm}$ ) for $1 \mathrm{PM}$ and $1.67 \mathrm{~mm}$ (range 0.3 to $3.9 \mathrm{~mm}$ ) for 2PM. Seventy-six teeth $(n=76)$, corresponding to upper 1PM and $2 \mathrm{PM}$ were evaluated in the 19 patients. 

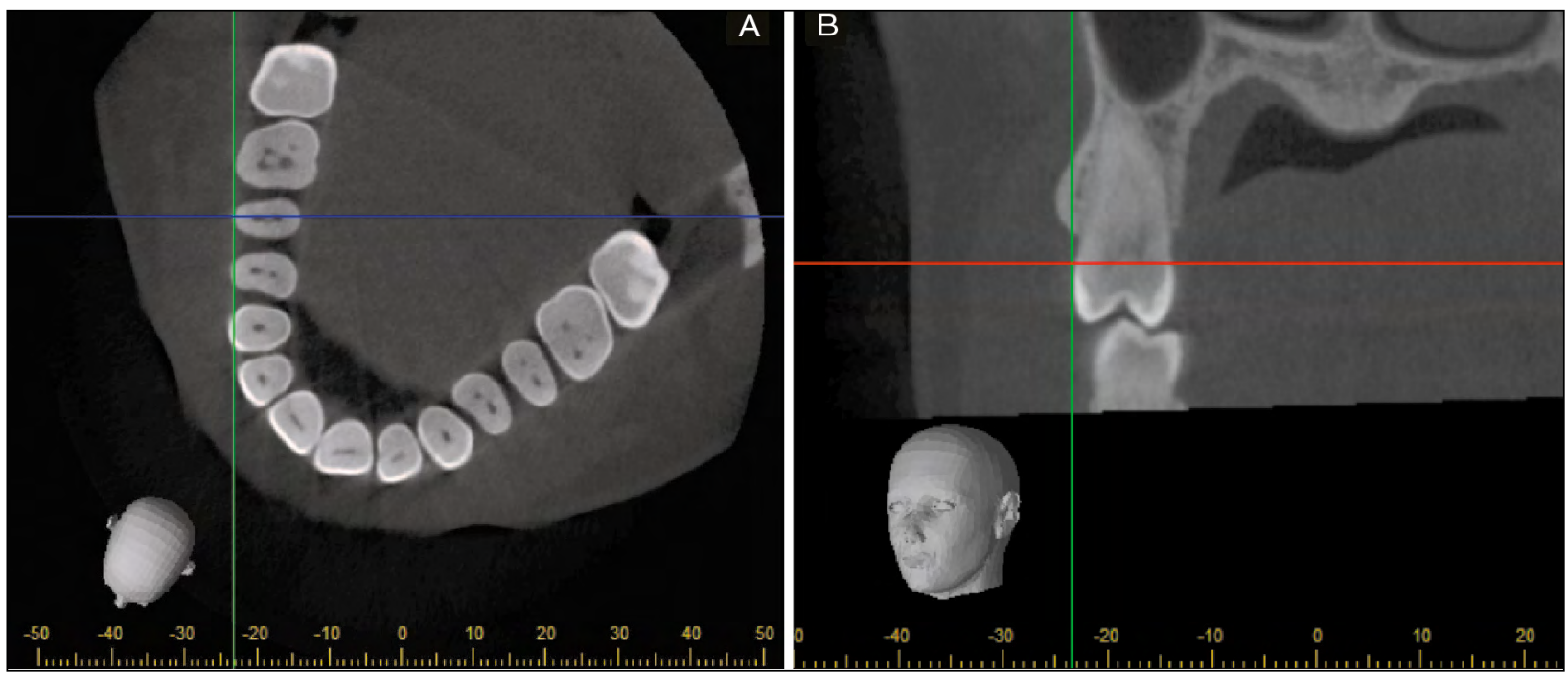

Fig. 1: a) Axial section: teeth main axis parallel to horizontal reference. b) Coronal section: line joining vestibular and palatine cementoenamel junctions coincides with horizontal axis.

Arithmetic mean distance CEJ-CC in 1PM was $3.05 \mathrm{~mm}$ (range $1.09 \mathrm{~mm}$ to $4.99 \mathrm{~mm}$ ) at $\mathrm{T} 0$, and remained at $3.05 \mathrm{~mm}$ at $\mathrm{T} 1$ (range $0.41 \mathrm{~mm}$ to 5.57 $\mathrm{mm}$ ). Arithmetic mean distance CEJ-CC in 2PM was $2.06 \mathrm{~mm}$ (range $1.04 \mathrm{~mm}$ to $4.66 \mathrm{~mm}$ ) at $\mathrm{T} 0$ and 2.31 (range 1.07 to 5.23 ) at T1.

For a descriptive analysis of the distance CEJ-CC, results were grouped into two categories (Table 1):

- Positive response (difference between T0 and $\mathrm{T} 1 \leq 0.5 \mathrm{~mm})$

- Negative response (difference between T0 and $\mathrm{T} 1>0.5 \mathrm{~mm}$ ).

Of the $381 \mathrm{PM}, 31(81.6 \%)$ showed a difference $\leq 0.5$ $\mathrm{mm}$ between $\mathrm{T} 0$ and $\mathrm{T} 1$. This variation indicates that the distance CEJ-CC remained the same or decreased, a positive response. Seven 1PM (18.4\%) showed a difference $>0.5 \mathrm{~mm}$ between $\mathrm{T} 0$ and $\mathrm{T} 1$, a negative response. Of the $382 \mathrm{PM}, 26(68.4 \%)$ showed a difference $\leq 0.5 \mathrm{~mm}$ between $\mathrm{T} 0$ and $\mathrm{T} 1$ and 12 2PM (31.6\%) showed a difference $>0.5 \mathrm{~mm}$ between $\mathrm{T} 0$ and $\mathrm{T} 1$.

Initial facial bone thickness for 1PM ranged from $0.00 \mathrm{~mm}$ to $2.04 \mathrm{~mm}$ (average $0.80 \mathrm{~mm}$ ) at CEJ+4 and from $0.40 \mathrm{~mm}$ to $2.85 \mathrm{~mm}$ (average $0.88 \mathrm{~mm}$ ) at CEJ+6. For 2PM, it ranged from $0.00 \mathrm{~mm}$ to 3.06 $\mathrm{mm}$ (average $1.59 \mathrm{~mm}$ ) at CEJ+4 and $0.60 \mathrm{~mm}$ to $3.94 \mathrm{~mm}$ (average $1.61 \mathrm{~mm}$ ) at CEJ+6.

For analysis of bone thickness, the following categories were established (Table 2):

- Undetectable bone wall

- Thickness $<0.5 \mathrm{~mm}$

- Thickness $\geq 0.5 \mathrm{~mm}$
Analysis of the post-expansion bone thickness showed the following: Of the $381 \mathrm{PM}$, at CEJ+ 4, of 31 sites with thickness $\geq 0.5 \mathrm{~mm}$ (T0), 28 remained in that group and in 3 sites no detectable wall was found. One site with thickness $<0.5 \mathrm{~mm}$ (T0) increased its thickness to $\geq 0.5 \mathrm{~mm}$. Of 6 sites with no detectable wall (T0), 1 increased its thickness. At CEJ+ 6, of 34 sites with thickness $\geq 0.5 \mathrm{~mm}$ (T0), 32 remained in that group and at 2 sites the thickness decreased to $<0.5 \mathrm{~mm}$. Of the 4 sites with thickness $<0.5 \mathrm{~mm}$ (T0), 2 increased their thickness to $\geq 0.5$ $\mathrm{mm}$. In 2PM, at CEJ+ 4, of 36 sites with thickness $\geq 0.5 \mathrm{~mm}$ (T0), only one site had an undetectable wall. Of 2 sites with undetectable thickness (T0), one increased its thickness to $\geq 0.5 \mathrm{~mm}$. In CEJ+ 6 , of the 38 sites with thickness $\geq 0.5 \mathrm{~mm}$ (T0), 32

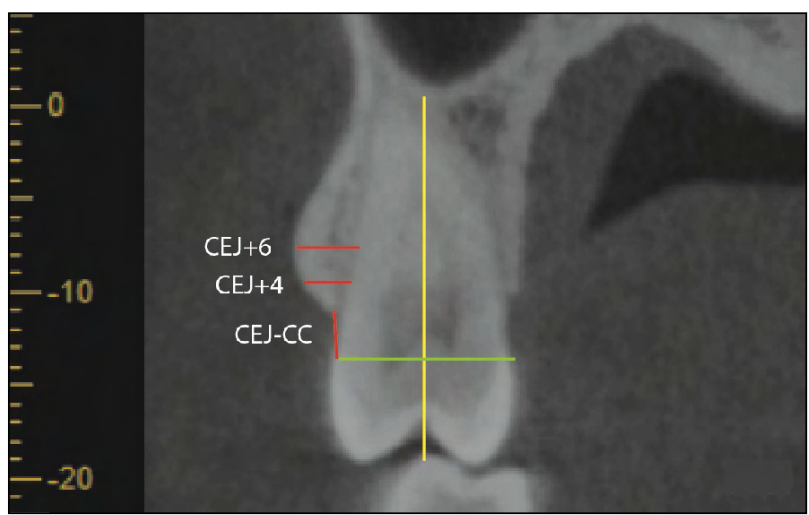

Fig. 2: Coronal section of upper premolars: distance from cementoenamel junction to alveolar crest (CEJ-CC) and thickness of facial bone 4 and $6 \mathrm{~mm}$ apical to the CEJ (CEJ+4 and $C J+6$, respectively). 

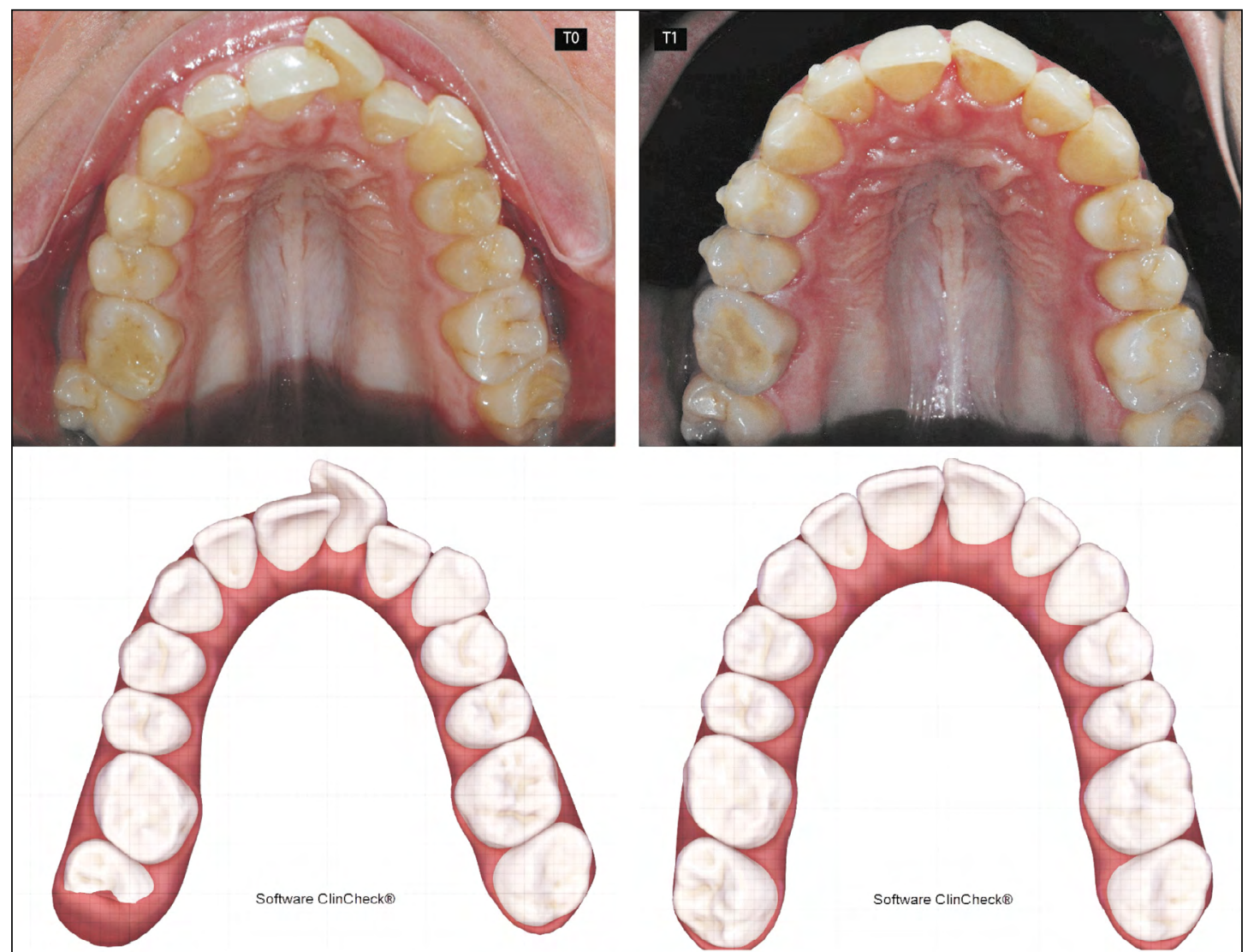

\begin{tabular}{|c|c|c|c|}
\hline & T0 & T1 & DIF \\
\hline 1.4-2.4 width & $31.3 \mathrm{~mm}$ & $34.8 \mathrm{~mm}$ & $3.5 \mathrm{~mm}$ \\
\hline 1.5-2.5 width & $35.8 \mathrm{~mm}$ & $38.8 \mathrm{~mm}$ & $3 \mathrm{~mm}$ \\
\hline
\end{tabular}

Fig 3: Clinical and virtual models (Clincheck $®)$ images showing transverse changes between T0 and T1.
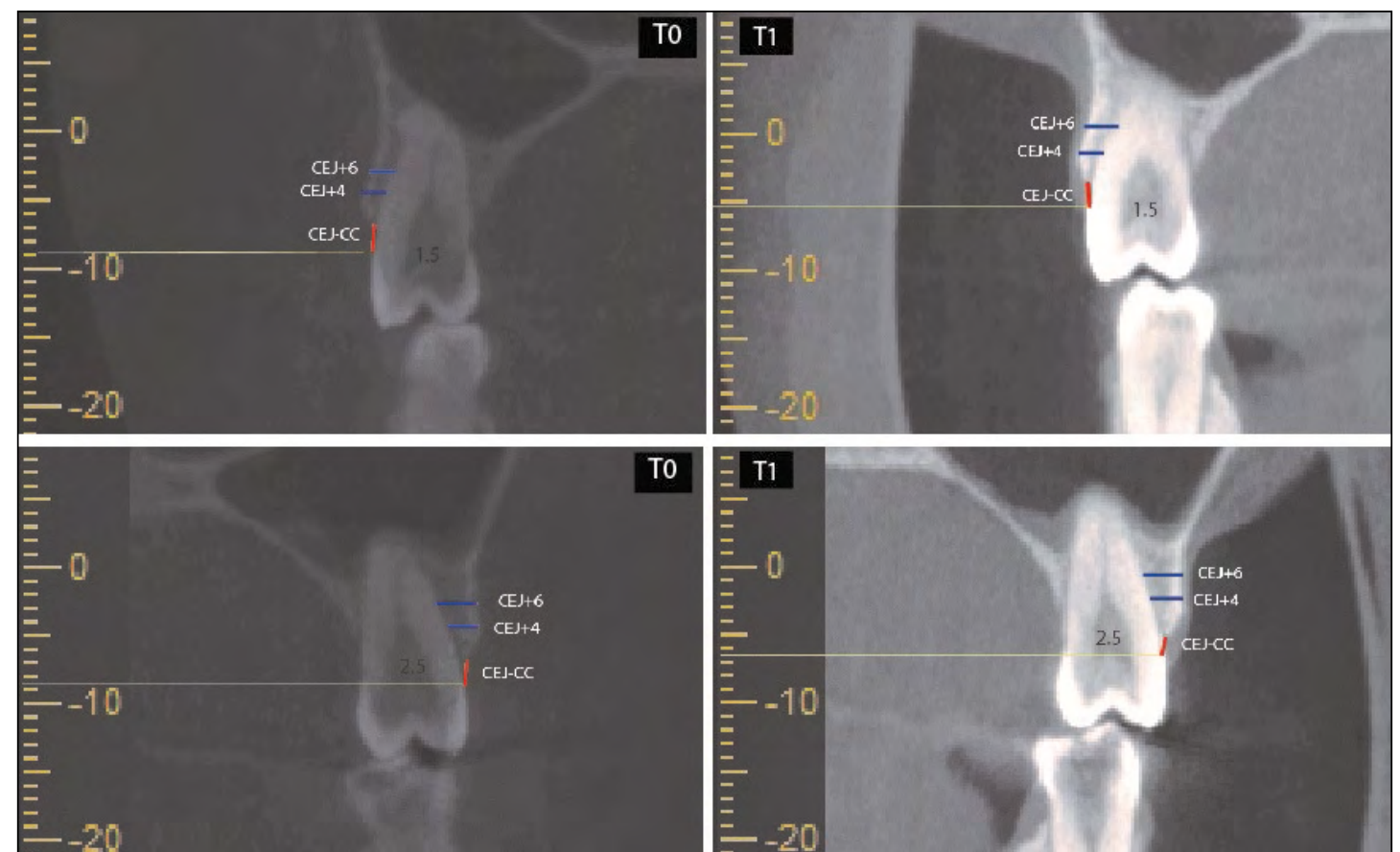

Fig 4: Tomographic images at TO and T1. 


\section{Table 1. Changes in CEJ-CC measurements

\begin{tabular}{|c|c|c|c|c|} 
& \multicolumn{2}{|c|}{$\begin{array}{c}\text { Positive response } \\
\mathbf{5 0 . 5} \mathbf{~ m m}\end{array}$} & \multicolumn{2}{|c|}{$\begin{array}{c}\text { Negative response } \\
\mathbf{> 0 . 5} \mathbf{~ m m}\end{array}$} \\
\hline & Sites & $\%$ & Sites & $\%$ \\
\hline 1PM & 31 & 81.6 & 7 & 18.4 \\
\hline 2 PM & 26 & 68.4 & 12 & 31.6 \\
\hline
\end{tabular}

remained in that group, 5 became $<0.5 \mathrm{~mm}$ thick and one was not detectable.

Figs. 5 and 6 provide data for bone height and thickness at the beginning of treatment and postexpansion.

The minimal changes in the clinical records (GI, PI, PPD and CAL) between T0 and T1 were compatible with the maintenance of gingival-periodontal health (Figs. 7 and 8). Regarding CAL, of the 76 evaluated sites, 6 lost insertion ( 4 of them lost $1 \mathrm{~mm}$ and the other 2 lost $2 \mathrm{~mm}$ ).

\section{DISCUSSION}

The aim of this study was to analyze the changes in periodontal health status and the effects on maxillary facial bone after the first year of orthodontic expansion using the Invisalign ${ }^{\circledR}$ clear aligner therapy. Although we found some studies that analyzed alveolar bone height and/or thickness, none of them correlated this information with clinical parameters ${ }^{7,15}$.

The presence of facial bone - both height and thickness - is crucial because it supports the gingival margin, providing it with stability over time, and determines its esthetic outline. If this wall is lost, bone dehiscence or gingival recessions may develop. It is therefore essential to evaluate its dimensions prior to beginning orthodontic therapy with expansion (either bodily or tipping movement).
Information provided by CBCT is useful for making the diagnosis and designing an appropriate treatment plan with an expansion requirement. The thickness of the bone plate that covers teeth in buccal and palatal aspects is one of the limiting factors of tooth movement ${ }^{4}$.

In our study, facial bone thickness and height in maxillary premolars were examined by using CBCT, which provides $0.123 \mathrm{~mm}$ image resolution, enabling precise linear measurements with low exposure to radiation. Thicknesses under $0.12 \mathrm{~mm}$ might not be detected.

Ali et al. ${ }^{9}$ reported that the range of dental expansion should be $2-3 \mathrm{~mm}$ per quadrant to reduce the risk of gingival recession. In the present study, the prescribed amount of expansion for each participant was customized based on measurements of the dentition and CBCT, in order to be within a safe range and to design an accurate treatment plan. The average expansion was $1.93 \mathrm{~mm}$ for 1PM (range 0.5 to $5.1 \mathrm{~mm}$ ) and $1.67 \mathrm{~mm}$ for 2PM (range 0.3 to 3.9 $\mathrm{mm})$.

In our study, facial bone height was measured by evaluating the distance from the $\mathrm{CEJ}$ to the $\mathrm{CC}$, and its thickness was measured at two levels: CEJ+4 and CEJ+6, in 38 first upper premolars and 38 upper second premolars. For 1PM, our average value for the CEJ-CC distance was $3.05 \mathrm{~mm}$ at T0, similar to the value found in a study by $\operatorname{Vera}^{23}(2.79 \mathrm{~mm})$, who analyzed facial bone wall dimensions in anterior maxillary arch between and including 1PM. Wang et al. ${ }^{5}$ also analyzed facial bone wall dimensions of maxillary anterior teeth and premolars using CBCT, and their findings were lower than Vera's and ours. Height was measured from CEJ to CC and ranged from $0.1 \mathrm{~mm}$ to $4 \mathrm{~mm}$; the mean distance was 2.2 $\pm 0.7 \mathrm{~mm}$ for $1 \mathrm{PM}$ and $2.0 \pm 0.6 \mathrm{~mm}$ for $2 \mathrm{PM}$.

\begin{tabular}{|c|c|c|c|c|c|c|c|c|}
\hline & \multicolumn{2}{|c|}{ 1PM CEJ+4 } & \multicolumn{2}{|c|}{ 1PM CEJ+6 } & \multicolumn{2}{|c|}{ 2PM CEJ+4 } & \multicolumn{2}{|c|}{ 2PM CEJ+6 } \\
\hline & TO & $\mathrm{T} 1$ & TO & T1 & TO & T1 & TO & T1 \\
\hline & Sites & Sites & Sites & Sites & Sites & Sites & Sites & Sites \\
\hline $\begin{array}{l}\text { UNDETECT. } \\
\text { WALL }\end{array}$ & $\begin{array}{c}6 \\
(15.8 \%)\end{array}$ & $\begin{array}{c}8 \\
(21 \%)\end{array}$ & $\begin{array}{c}0 \\
(0 \%)\end{array}$ & $\begin{array}{c}0 \\
(0 \%)\end{array}$ & $\begin{array}{c}2 \\
(5.3 \%)\end{array}$ & $\begin{array}{c}1 \\
2.6\end{array}$ & $\begin{array}{c}0 \\
(0 \%)\end{array}$ & $\begin{array}{c}0 \\
(0 \%)\end{array}$ \\
\hline $\begin{array}{c}\text { THICKNESS } \\
<0.5 \mathrm{~mm}\end{array}$ & $\begin{array}{c}1 \\
(2.6 \%)\end{array}$ & $\begin{array}{c}1 \\
(2.6 \%)\end{array}$ & $\begin{array}{c}4 \\
(10.5 \%)\end{array}$ & $\begin{array}{c}4 \\
(10.5 \%)\end{array}$ & $\begin{array}{c}0 \\
(0 \%)\end{array}$ & $\begin{array}{c}0 \\
(0 \%)\end{array}$ & $\begin{array}{c}0 \\
(0 \%)\end{array}$ & $\begin{array}{c}5 \\
(13.1 \%)\end{array}$ \\
\hline $\begin{array}{c}\text { THICKNESS } \\
\geq 0.5 \mathrm{~mm}\end{array}$ & $\begin{array}{c}31 \\
(81.6 \%)\end{array}$ & $\begin{array}{c}29 \\
(76.4 \%)\end{array}$ & $\begin{array}{c}34 \\
(89.5 \%)\end{array}$ & $\begin{array}{c}34 \\
89.5\end{array}$ & $\begin{array}{c}36 \\
(94.7 \%)\end{array}$ & $\begin{array}{c}37 \\
(97.4 \%)\end{array}$ & $\begin{array}{c}38 \\
(100 \%)\end{array}$ & $\begin{array}{c}33 \\
(86.9 \%)\end{array}$ \\
\hline
\end{tabular}




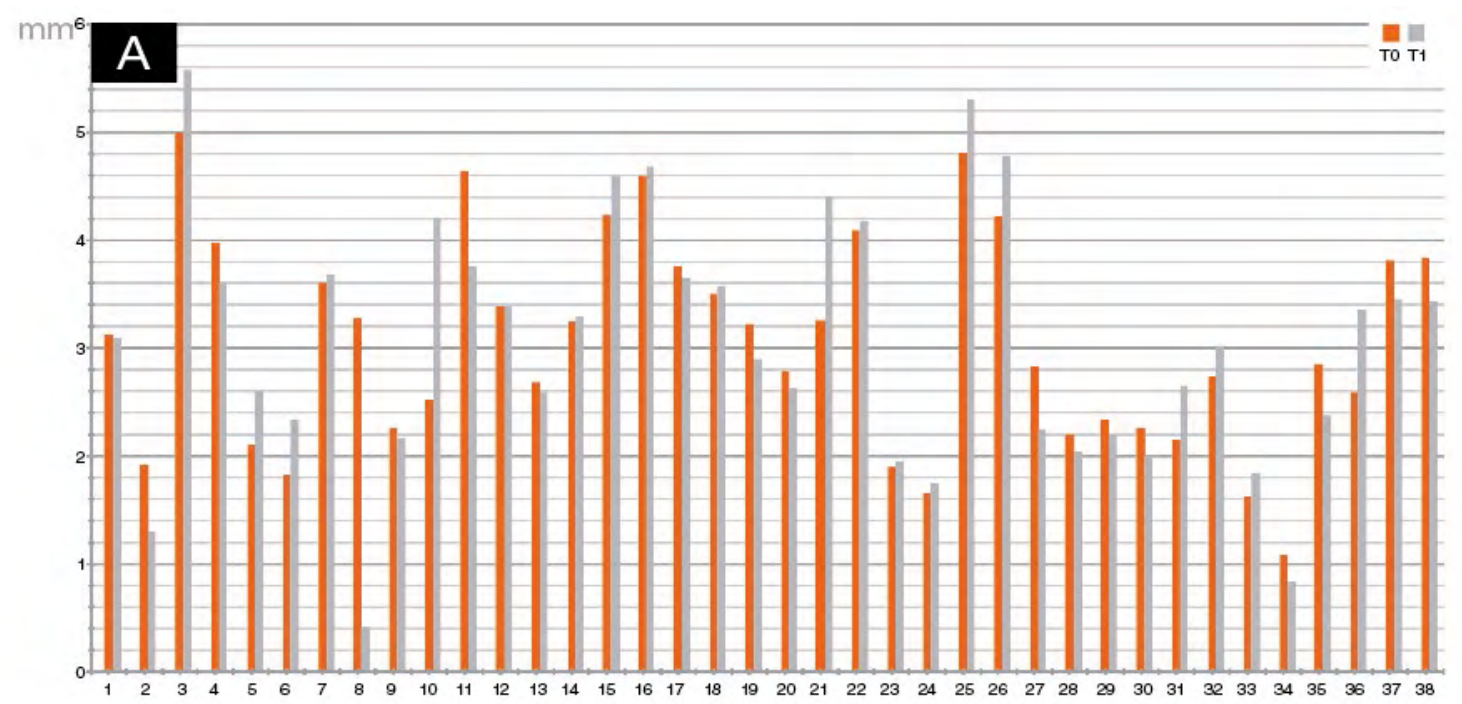

$\mathrm{mm}^{2}$

$\mathrm{B}$

To $\mathrm{T} 1$

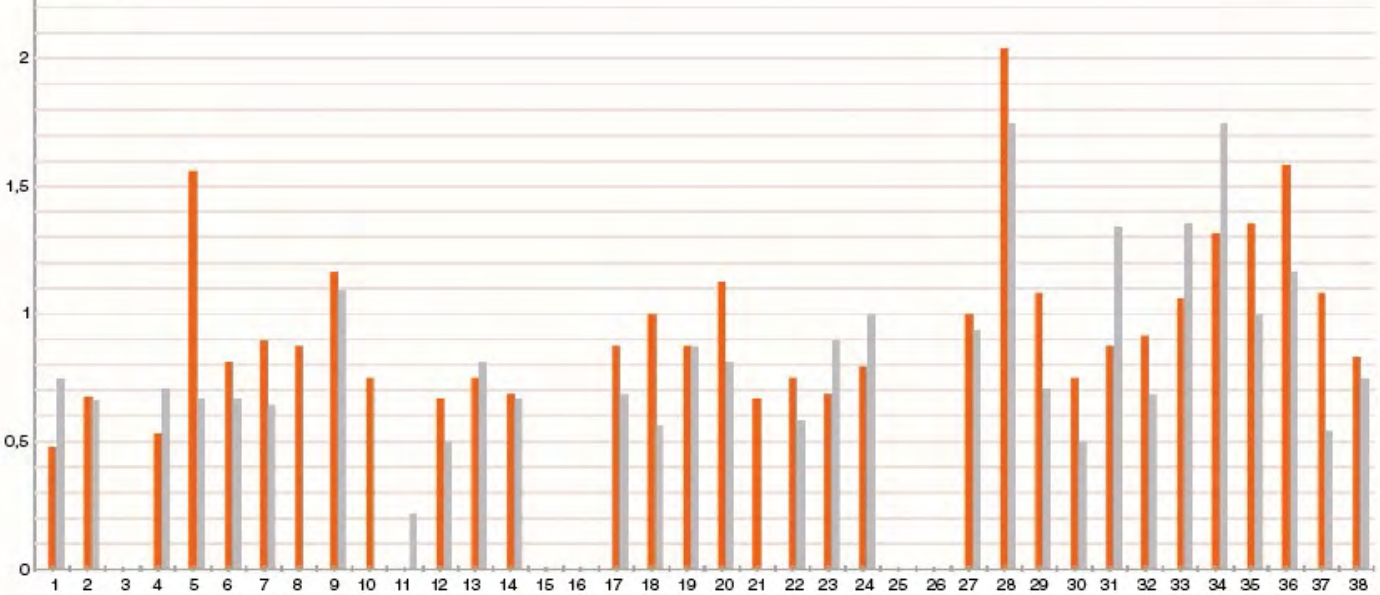

$\mathrm{mm}$
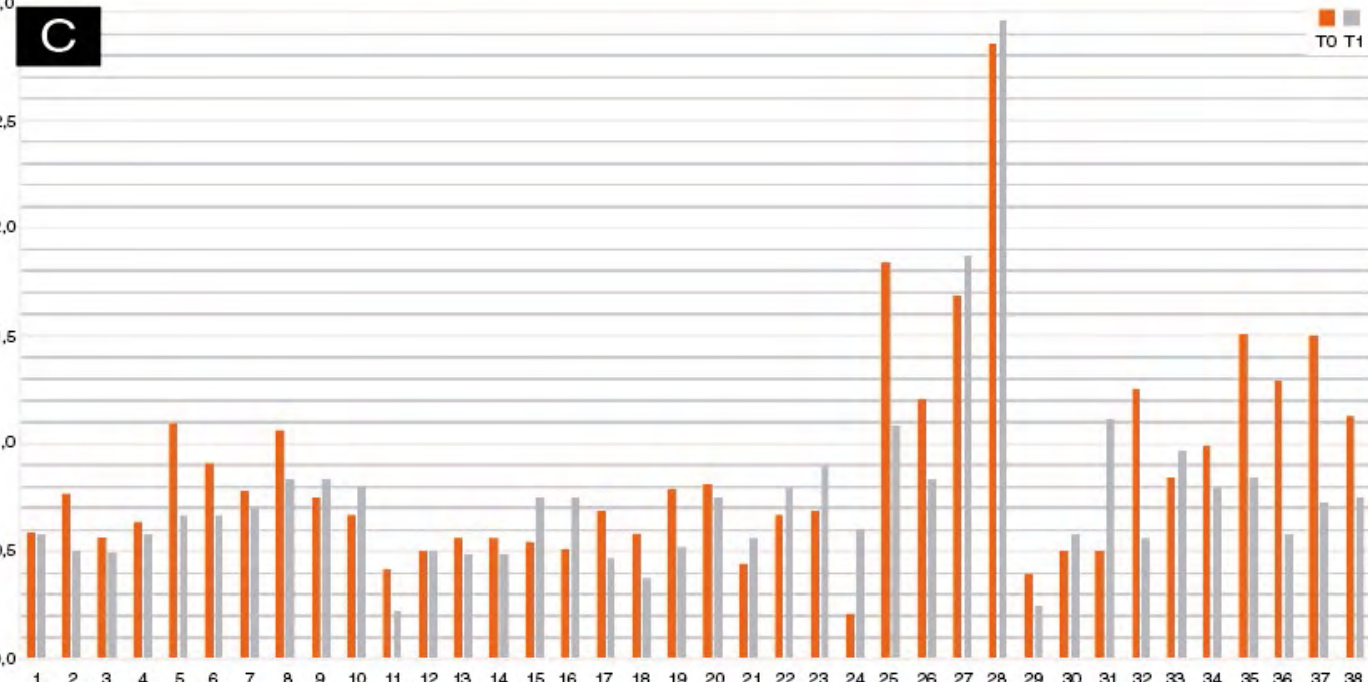

Fig 5: Tomographic measurements in IPM at T0 and T1 for all teeth studied. A) Distance CEJ-CC. B) Facial plate thickness at CEJ+4. C) Facial plate thickness at CEJ+6 

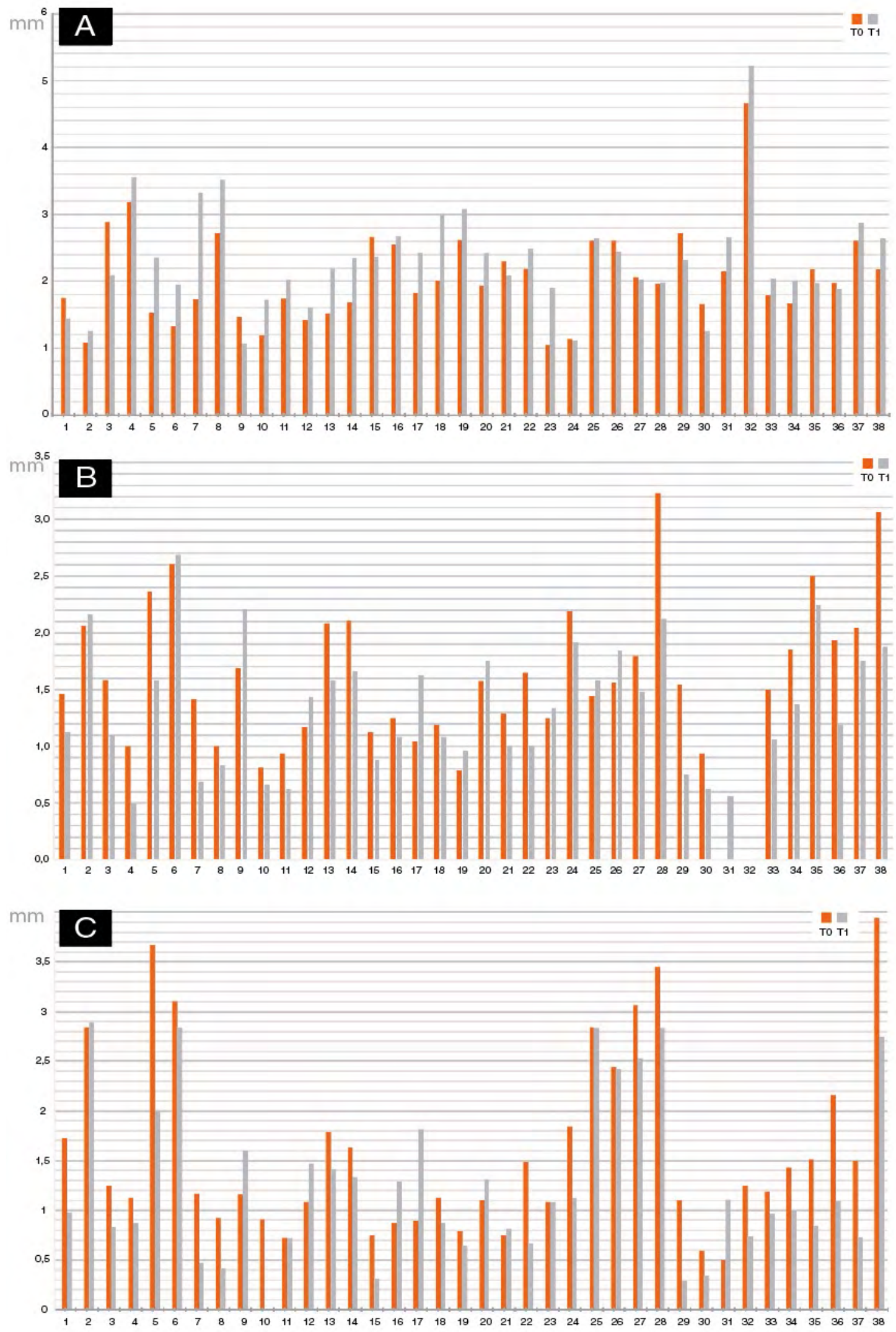

Fig 6: Tomographic measurements in 2PM at T0 and T1 for all teeth studied. A) Distance CEJ-CC. B) Facial plate thickness at CEJ+4. C) Facial plate thickness at CEJ+6 
To T1

$\mathrm{mm} \quad 2,5$

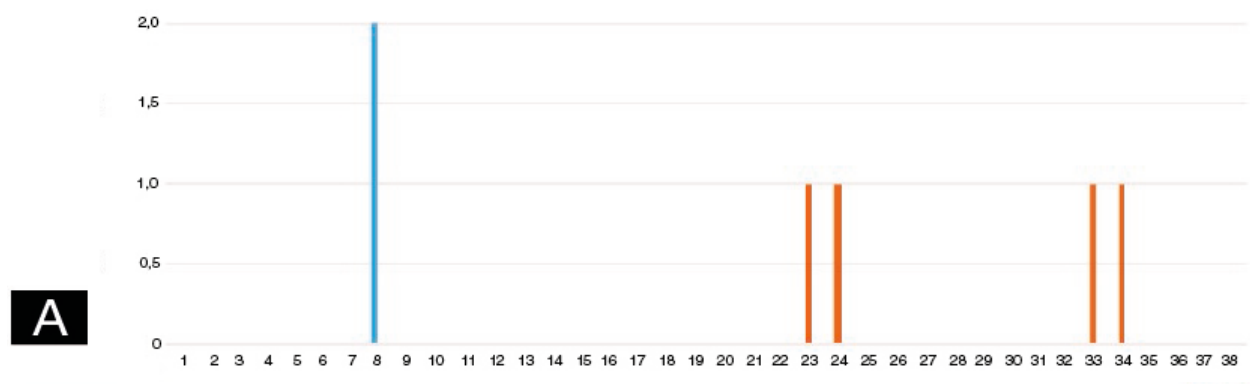

$\mathrm{mm} \quad 1,2$

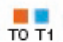
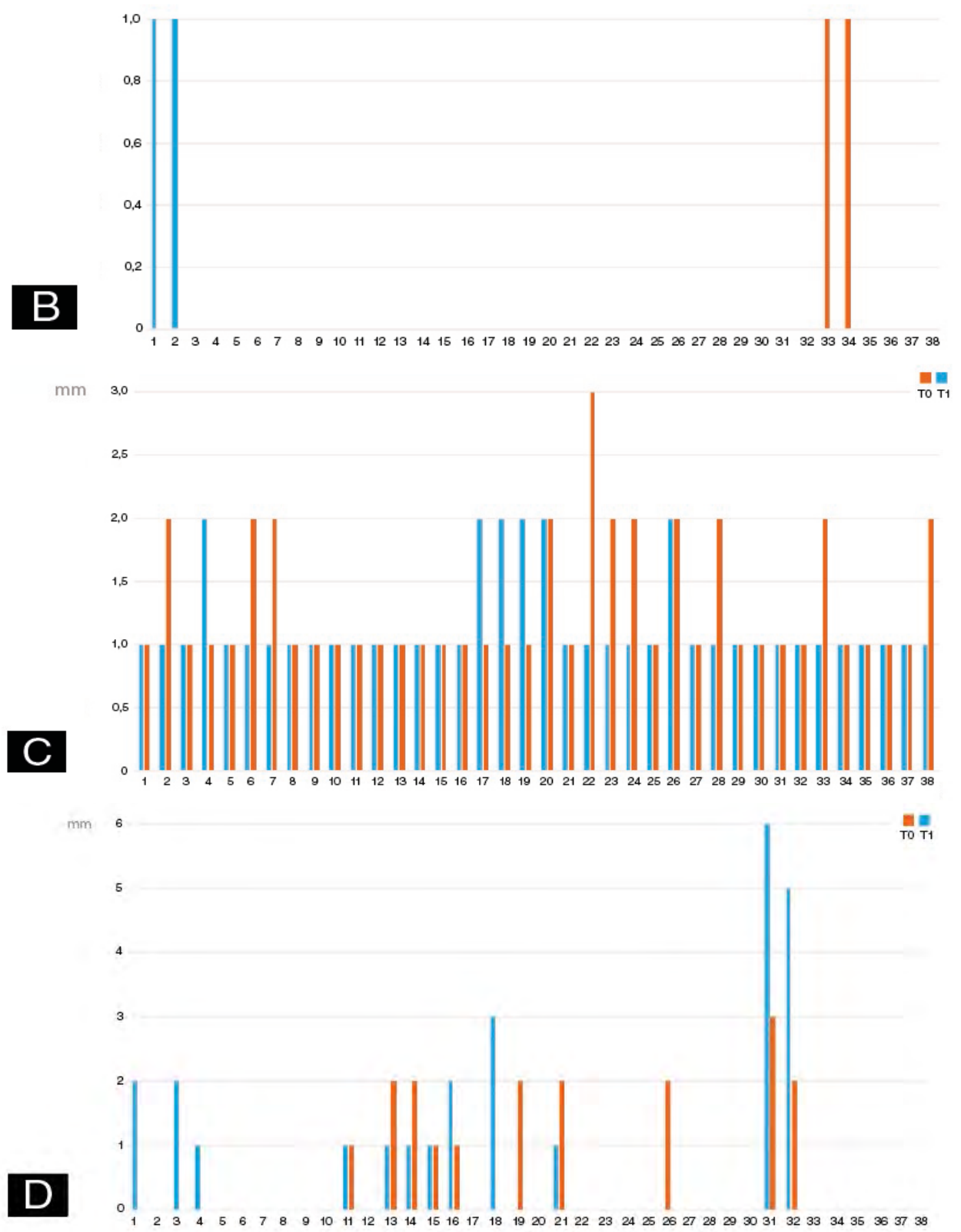

Fig 7: Clinical records in 1PM at T0 and T1 for all teeth studied. A) Gingival index (GI). B) Plaque index (PI). C) Probing pocket depth (PPD). D) Clinical attachment level (CAL) 
$\mathrm{mm} \quad 2,5$

\section{A}

$$
0,5
$$

.5

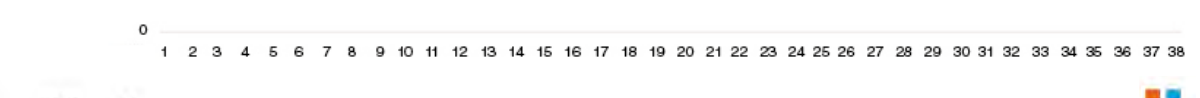

$\mathrm{mm} \quad 1,2$
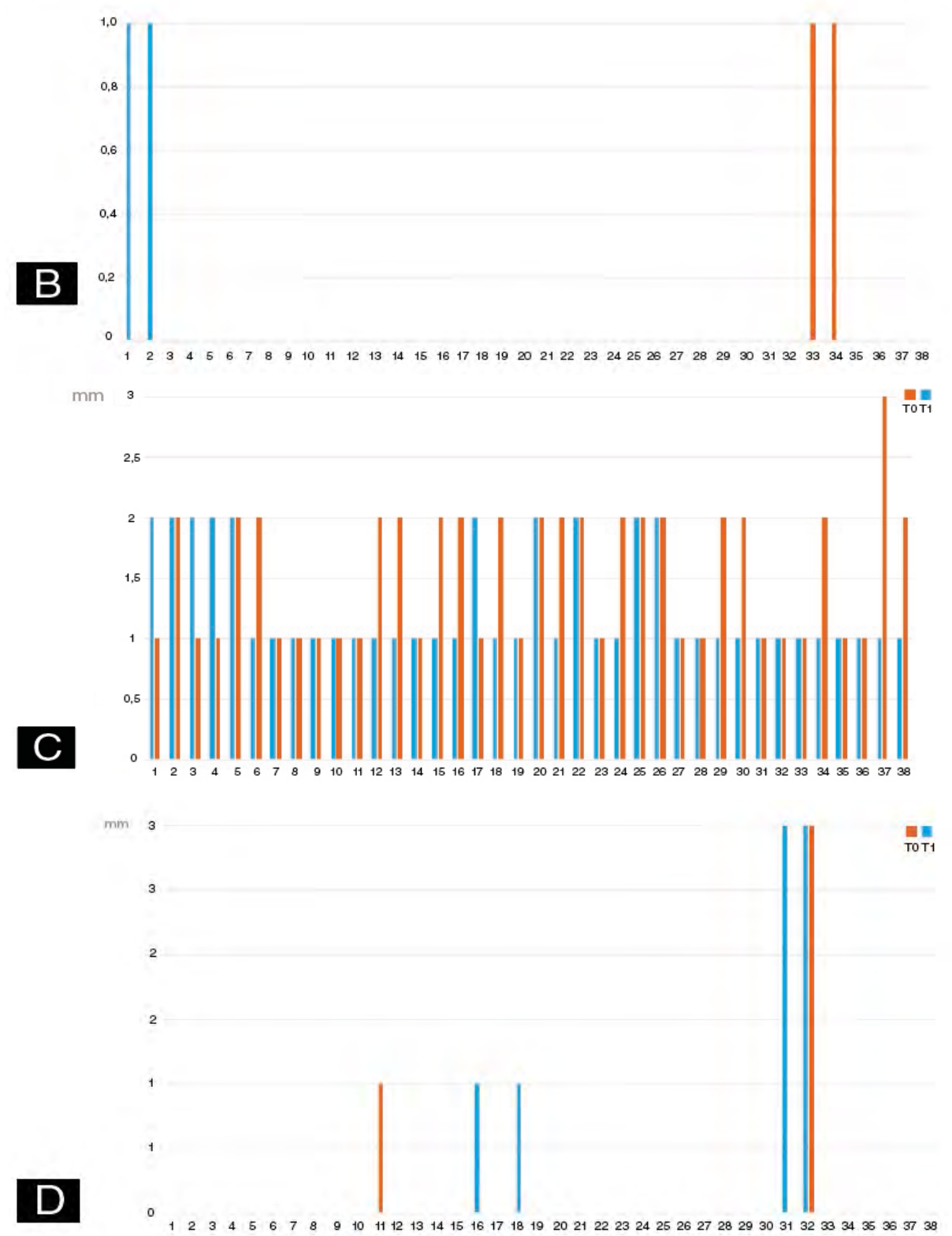

Fig 8: Clinical records in 2PM at T0 and T1 for all teeth studied. A) Gingival index (GI). B) Plaque index (PI). C) Probing pocket depth (PPD). D) Clinical attachment level (CAL) 
Post-expansion for 1PM, the CEJ-CC distance remained unchanged or diminished at 31 of the 38 evaluated sites, meaning that the level of insertion remained the same or increased at these sites, considered to be a positive response. However, it increased at 7 sites, reflecting a decrease in the level of insertion. For 2PM, there were 26 sites with a positive response, while 12 showed a decrease in level of insertion. According to Castro et al. ${ }^{3}$, the association between orthodontic treatment and changes in the distance between CEJ-CC has been widely studied, but the difference in orthodontic techniques, the various criteria for radiographic evaluation, and the several methods of diagnostic imaging used in the different studies have limited the comparison of results ${ }^{12}$.

For facial bone thickness, Vera $^{23}$ reports that the median buccal alveolar bone thickness $1 \mathrm{~mm}$ apical to the alveolar bone crest was $1.13 \mathrm{~mm}$; and at the midroot it was $1.03 \mathrm{~mm}$ in the premolar area. Temple et al. ${ }^{18}$ analyzed the thickness at $1 \mathrm{~mm}, 3 \mathrm{~mm}$ and $5 \mathrm{~mm}$ apical to $\mathrm{CC}$ of the posterior teeth, finding an average of $0.72 \mathrm{~mm}$ for $1 \mathrm{PM}$ at $3 \mathrm{~mm}$ and $1.24 \mathrm{~mm}$ for $2 \mathrm{PM}$. In our study, the initial values for $1 \mathrm{PM}$ (average $0.80 \mathrm{CEJ}+4$ and $0.88 \mathrm{CEJ}+6$ ) and for 2PM (average $1.59 \mathrm{CEJ}+4$ and $1.61 \mathrm{CEJ}+6$ ) agree with Temple et al. ${ }^{18}$, being lower than $1 \mathrm{~mm}$, with many of them having a wall thinner than $0.5 \mathrm{~mm}$.

Braut et al. ${ }^{11}$ analyzed the thickness of buccal bone of anterior teeth including $1 \mathrm{PM}$ at two locations: $4 \mathrm{~mm}$ and midroot. They found absence of buccal wall in $17.5 \%$ of the cases for $1 \mathrm{PM}$ measured at $4 \mathrm{~mm}$ to the CEJ. Average thickness was $0.73 \mathrm{~mm}$ at $4 \mathrm{~mm}$ and $0.75 \mathrm{~mm}$ at midroot. Similarly, in our sample, no buccal wall was detected in $15.8 \%$ of 1PM, and the thickness measurements were similar. Cattaneo et al. ${ }^{15}$ assessed transverse changes in upper arch as a result of using passive and active self-ligating brackets. They performed greater transversal increase in the interfirst premolar width $(4.3 \mathrm{~mm}$ and $4.5 \mathrm{~mm})$ and intersecond premolar width (4 $\mathrm{mm}$ and $3.3 \mathrm{~mm}$ ) respectively; thus, they found the buccal bone area for 2PM decreased on average 14 to $20 \%$ post-dentoalveolar expansion. The buccal bone for 1PM was so thin that the error of the method surpassed the mean measured value, for which reason only the bone in the $2 \mathrm{PM}$ region was evaluated.

In our study, for 2PM, there was a slight increase in thickness at CEJ+4 (2.7\% improvement), while there was a reduction of $13.1 \%$ at $\mathrm{CEJ}+6$ at $\mathrm{T} 1$. The different measurement methods, statistical evaluation, appliances and expansion amounts limit the comparison of the results of these two studies. Ibiapina et al. $^{7}$ evaluated changes in transverse dimensions of upper arch and thickness of the buccal bone plate in patients undergoing orthodontic treatment with conventional and selfligating brackets, at $\mathrm{CEJ}+3 \mathrm{~mm}$ and $\mathrm{CEJ}+6 \mathrm{~mm}$. The expansion was $1.57 \mathrm{~mm}$ and $1.77 \mathrm{~mm}$ for interfirst premolar, and $1.08 \mathrm{~mm}$ and $1.88 \mathrm{~mm}$ for intersecond premolar. They observed that a small decrease of the buccal bone occurred similarly in both groups. Our study presents an average expansion similar to Ibiapina's and the results are in agreement with that study, having found a slight decrease of only $5.2 \%$ for first PM at CEJ+4mm.

Karkhanechi et al. ${ }^{2}$ report that treatments with fixed orthodontic appliances increase plaque accumulation and can interfere with oral hygiene procedures. A shift is observed from Gram+ aerobic species (associated with periodontal health) to Gram- anaerobic or facultative species (associated with periodontitis). In agreement with the study by Levrini et al. ${ }^{27}$, which claims that CAT facilitates adequate oral hygiene, thereby reducing the risk of gingival-periodontal complications, our study showed that PI, GI, PPD and CAL remained stable. Regarding PI, for 1PM, 2 sites scored 1 at T0 and at T1. The same was true for 2PM. Regarding GI, for $1 \mathrm{PM}$, at T0 the score was 0 at 37 sites and 2 at one site, while at T1 it was 1 at four sites. For 2PM, it was 0 at all sites at both times. Average PPD for $1 \mathrm{PM}$ was 1.16 at $\mathrm{T} 0$ and 1.32 at $\mathrm{T} 1$, while for $2 \mathrm{PM}$ it was 1.26 at $\mathrm{T} 0$ and 1.53 at $\mathrm{T} 1$, which evidences the maintenance of periodontal health. Average clinical CAL was $0.68 \mathrm{~mm}$ at $\mathrm{T} 0$ and 0.47 at $\mathrm{T} 1$ for $1 \mathrm{PM}$, and $0.21 \mathrm{~mm}$ at $\mathrm{T} 0$ and $0.11 \mathrm{~mm}$ at $\mathrm{T} 1$ for $2 \mathrm{PM}$. In both groups, CAL declined, which is considered to be a clinical improvement.

With regard to the association between attachment loss and increase in distance from CEJ to CC, only one site showed positive correlation. At the sites where the CEJ-CC distance was found to increase, it could be a due to thin periodontal phenotype and the very thin initial buccal bone thickness. Nevertheless, no clinical correlation was found, possibly due to the formation of a long junctional epithelium and/ or gingival contraction which prevented probe penetration. 
Despite the risk of expansion in patients with a very thin buccal bone and crowding, this treatment was chosen because it provides improvements for oral hygiene and a decrease in the accumulation of bacterial plaque, guaranteeing the health of periodontal tissues for the future.

Further studies are needed to observe the behavior of periodontal tissues using larger samples and a longer follow-up period.

\section{ACKNOWLEDGMENTS}

The authors express their gratitude to the following for their valuable collaboration in this study: D.D.S. Ricardo L. Macchi and Hugo M. Dagum as consultants, D.D.S. Liliana Rodríguez Bueno, Authorities of S.A.O.-U.C.E.S (Sociedad Argentina de Ortodoncia - Universidad de Ciencias Empresariales y Sociales); D.D.S. Gabriela Caldentey, Rocío Moreno and Eliane Binder; librarian Ms. Karina Lloveras for her assistance in literature references search; Clinical Dental Assistant Ms. Rosalba Gómez and Instituto Radiológico Dental Dr. Hugo Dagum.

\section{REFERENCES}

1. Barreda G, Dzierewianko E, Munoz K, Piccoli G. Surface wear of resin composites used for Invisalign(r) attachments. Acta Odontol Latinoam 2017; 30: 90-95.

2. Karkhanechi M, Chow D, Sipkin J, Sherman D, Boylane R, Norman R. Periodontal status of adult patients treated with fixed buccal appliances and removable aligners over one year of active orthodontic therapy. Angle Orthod 2013; 83: 146-151.

3. Castro LO, Castro IO, Valladares-Neto J, Estrela C. Cone beam computed tomography evaluation of distance from cementoenamel junction to alveolar crest before and after nonextraction orthodontic treatment. Angle Orthod 2016; 86: 543-550.

4. Ferreira MC, Gamba Garib D, Catrim-Ferreira F. Method standarization of buccal and palatal arch bone plate measurement using Cone Beam Computed Tomography. Dental Press J Orthod 2010; 15: 49.e1-7. https://www. scielo.br/pdf/dpjo/v15n1/en_06.pdf

5. Wang HM, Shen JW, Yu MF,Chen XY, Jianq QH, He FM. Analysis of facial bone wall dimensions and sagittal root position in the maxillary esthetic zone: a retrospective study using cone beam computed tomography. Int J Oral Maxillofac Implants 2014; 29: 1123-1129.

6. Morais JM. Evaluation of maxillary buccal alveolar bone before and after orthodontic alignment without extractions: A cone beam computed tomographic study. Angle Orthod 2018; 88: 748-756.

7. Ibiapina DO. Assessment of Dental Arch Changes and Buccal Bone Thickness in Patients treated with Self-ligating Brackets. J Contemp Dent Pract 2016; 17: 434-439.

8. McAllister BS, Eshraghi VT. Cone-Beam Computed Tomography: An Essential Technology for Management

\section{CONCLUSION}

Using Invisalign ${ }^{\circledR}$ for expansion movements did not produce substantial changes in the evaluated periodontal clinical parameters or in the bone measurements.

Removable appliances reduce bacterial plaque retentive factors and favor adequate oral hygiene.

\section{FUNDING}

This research was supported by the University Research Award Program 2016 (Align Technology). The authors declare no conflict of interest.

\section{CORRESPONDENCE}

Dr. Graciela J. Barreda

Galileo 2460 PB 2 C.A.B.A.

(1425). Buenos Aires. Argentina

grabarreda@gmail.com. 5411-4807-4762.

of Complex Periodontal and Implant Cases. J Periodontol 2017; 88: 937-938.

9. Ali SA, Miethke HR. Invisalign, an innovative invisible orthodontic appliance to correct malocclusions: advantages and limitations. Dent Update 2012; 39: 254-256, 258-260.

10. Mandelaris GA, Scheyer ET, Evans M, Kim D et al. American Academy of Periodontology Best Evidence Consensus Statement on Selected Oral Applications for Cone-Beam Computed Tomography. J Periodontol 2017; 88: 939-945.

11. Braut V, Bomstein MM, Belser U, Buser D. Thickness of the anterior maxillary facial bone wall-a retrospective radiographic study using cone beam computed tomography. Int J Periodontics Restorative Dent 2011; 31: 125-131.

12. Bontá H, Carranza N, Gualtieri A, Rojas M. Morphological characteristics of the facial bone wall related to the tooth position in the alveolar crest in the maxillary anterior. Acta Odontol Latinoam 2017; 30: 49-56.

13. Evangelista K, Vasconcelos KF, Bumann A, Hirsch E, Nitka M, Silva MAG. Dehiscence and fenestration in patients with Class I and Class II Division 1 malocclusion assessed with cone-beam computed tomography. Am J Orthod Dentofacial Orthop 2010; 138: 133.e1-133.e7. doi: 10.1016/j.ajodo.2010.02.021.

14. Kapila SD, Nervina MJ. Alveolar Boundary Conditions in Orthodontic Diagnosis and Treatment Planning In: Kapila $\mathrm{SD}$, Cone beam computed tomography in Orthodontics: Indications, Insights and Innovations. Ames, IA: WileyBlackwell, 2014: 293-316.

15. Cattaneo P, Treccani, M, Carlson, K, Thorgeirsson, TM, Melsen, B. Transversal maxillary dento-alveolar changes in patients treated with active and passive self ligating brackets: a randomized clinical trial using CBCT-scans and digital models. Orthod Craniofac Res 2011; 14: 222-233. 
16. Lindhe, J. Periodontología Clínica.. Buenos Aires, Argentina: Editorial Médica Panamericana,1992..

17. Januario AL, Rodriguez Duarte W, Barriviera M, Mesti JC, Guimaraes Araujo M, Lindhe J. Dimension of the facial bone wall in the anterior maxilla: a cone-beam computed tomography study. Clin Oral Impl Res 2011; 1168-1171.

18. Temple KE, Schoolfield J, Noujeim ME, Huynh-Ba G, Lasho DJ, Mealey BL. A cone beam computed tomography study of buccal plate thickness of the maxillary and mandibular posterior dentition. Clin Oral Implants Res 2016; 27: 1072-1078.

19. Garlock DT, Buschang PH, Araujo EA, Behrents RG, Kim KB. Evaluation of marginal alveolar bone in the anterior mandible with pretreatment and posttreatment computed tomography in nonextraction patients. Am J Orthod Dentofacial Orthop 2016: 192-201.

20. Cook VT, Cook VC, Timock AM, Crowe JJ, Wang M, Covell DAJr. Accuracy of alveolar bone measurements from cone beam computed tomography acquired using varying settings. Orthod Craniofac Res 2015; 18: 127-136.

21. Timock AC, Timock AM, Cook VC, Mc Don. Accuracy and reliability of buccal bone height and thickness measurements from cone beam computed tomography imaging. $\mathrm{Am} \mathrm{J}$ Orthod Dentofacial Orthop 2011; 140: 734-744.

22. Rojo-Sanchis J, Viña-Almunia J, Peñarrocha-Oltra D, Peñarrocha-Diago M. Facial Alveolar Bone Width at the First and Second Maxillary Premolars in Healthy Patients: A Cone Beam Computed Tomography Study. J Oral Implantol 2017; 43: 261-265.
23. Vera C, De Kok IJ, Reinhold D, Limpiphipatanakorn P, Yap AKW, Tyndall D, Cooper LF. Evaluation of buccal alveolar bone dimension of maxillary anterior and premolar teeth: a cone beam computed tomography investigation. Int J Oral Maxillofac Implants 2012; 27: 1514-1519.

24. Han JY. A comparative study of combined periodontal and orthodontic treatment with fixed appliances and clear aligners in patients with periodontitis. $J$ Periodontal Implant Sci 2015; 45: 193-204.

25. Azaripour A, Weusmann J, Mahmoodi B, Peppas D, Gerlhold-Ay A, Van Noorden C, Willershausen B. Braces versus Invisalign: gingival parameters and patient's satisfaction during treatment: a cross-sectional study. $B M C$ Oral Health 2015; 15-69.

26. Rossini G, Parrini S, Castroflorio T, Deregibus A, Debernardi CL. Periodontal health during clear aligners treatment: a systematic review. Eur J Orthod 2014; 1-5.

27. Levrini L, Mangano A, Montanari P, Margherini S, Caprioglio A, Abbate GM. Periodontal health status in patientes treated with the Invisalign system and fixed orthodontic appliances: A 3 months clinical and microbiological evaluation. Eur $J$ Dent 2015; 9: 404-410.

28. Silness J, Loe H. Periodontal Disease in Pregnancy. Ii. Correlation between Oral Hygiene and Periodontal Condition. Acta Odontol Scand 1964; 21: 121-135.

29. Loe H, Silness J. Periodontal Disease in Pregnancy. I. Prevalence and Severity. Acta Odontol Scand 1963; 21:533-551. 